\title{
Experimental Investigation on FRP Composite Compression Members
}

\author{
Robert Yuan* \\ Department of Civil Engineering, Lamar University, USA
}

Received: 㠿 January 24, 2018; Published: 眥 February 06, 2018

*Corresponding author: Robert Yuan, Department of Civil Engineering, Lamar University, P.O. Box 10024, Beaumont, TX 77710-0024, USA

\section{Introduction}

In the last 25 years, fiber-reinforced polymer (FRP) composite materials have been considered to be used in various civil engineering applications such as the cooling tower system, waste water treatment plant, pedestrian bridges, reinforced concrete rebars, structure strengthening members, and some metallic sensitive specialized buildings. This review of study is only concentrated on the experimental investigation of GFRP composite compression members made from glass-fiber and polyester-based and vinylester-based polymers in a pultrusion process.

\section{Experimental Program}

The experimental program includes 300+GFRP composite compression members with various dimensions, length, and crosssection configurations. Two sections have closed configurations; square box and round sections, three sections have open configurations; wide-flange, angle and I-sections. The length varies from $0.33 \mathrm{~m}$ to $7 \mathrm{~m}$, the wall thickness of each members varies from $3 \mathrm{~mm}$ to $10 \mathrm{~mm}$. The compression members were tested in the lab with 3-5 specimens for each group. The objectives of the research are to determine the allowable compressive stress, ultimate load, the effective length, and mode of failure.

\section{Analysis and Discussion}

i. From the material point of view, the GFRP composite materials can be applied to civil engineering structures as long/short columns, and as structural bracing elements. Particularly in an adverse environmental conditions, because of the corrosion resistance nature of the material. The bearing capacity of the compression member can be improved if the material constituents are replaced by the higher quality of fiber such as carbon fibers and aramid fibers, and an advanced polymers such as epoxies, but the material cost for construction will also be increased.

ii. The ultimate load capacity and the mode of failure for GFRP composite compression members depend on the length and the cross-section configuration of the member. For a given length and section shape, the significant parameters are the slenderness ratio and the flange-width to thickness ratio.

iii. The Euler's curve established from the test shown the dividing line for long and short membersbased on slenderness ratio $(\mathrm{kl} / \mathrm{r})$. For various configurations the values of $\mathrm{kl} / \mathrm{r}$ are presented as follows (Table).

Table:

\begin{tabular}{|c|c|c|c|c|}
\hline \multicolumn{2}{|c|}{ Cross Section } & \multicolumn{3}{c|}{ Open Section } \\
\hline square box & round tube & wide-flange & angle & I-section \\
\hline $\mathrm{kl} / \mathrm{r}=35$ & $30-40$ & $\mathrm{kl} / \mathrm{r}=40-60$ & $45-60$ & $30-40$ \\
\hline
\end{tabular}

iv. In general, the bearing strength of GFRP is about 200Mpa.

For closed section, the square box and round tube sections have shown bearing failure for short members and buckling failure for long members. For open section, the wide-flange, angle and I-sections have indicated bearing and/or local buckling failure mode for short and local/global bucking mode of failure for long compression members.

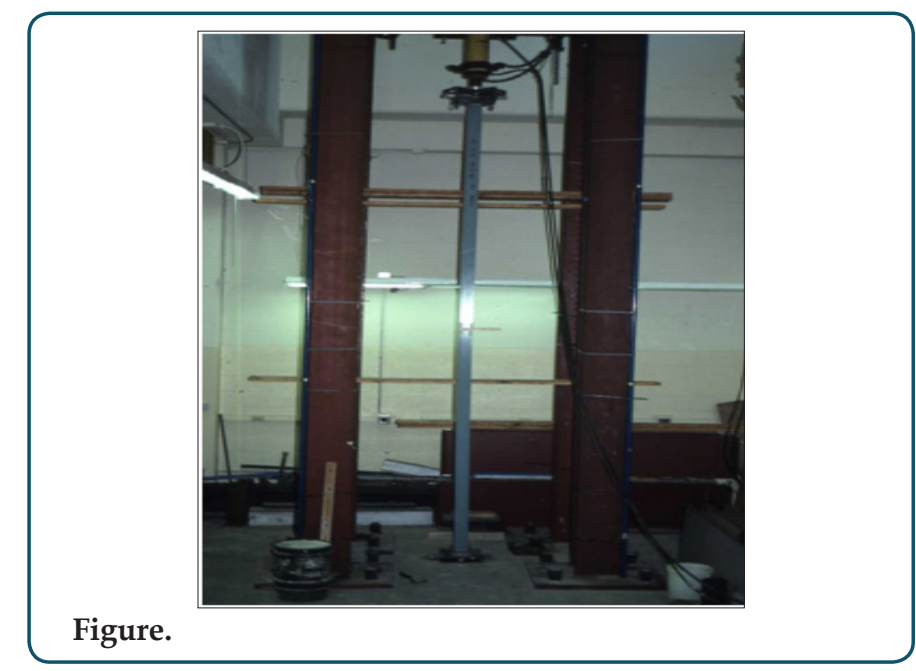


v. Compression members with I-sections have shown a sudden failure by global buckling at no warning in any fashion. It is recommended that the application of I-section compression members needs to be cautious (Figure).

vi. One of the interesting observation is that, the moment before failure, particularly for long compression members, a light color appears and reflected on the surface under the illumination of the lab. This phenomenon may be attributed to the stress level changes or high stress concentration at the position of failure. A photo-elasticity approach analysis may be interested in looking into the results.

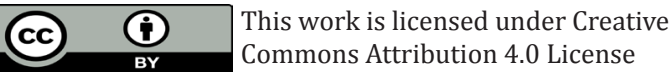

To Submit Your Article Click Here:

Submit Article

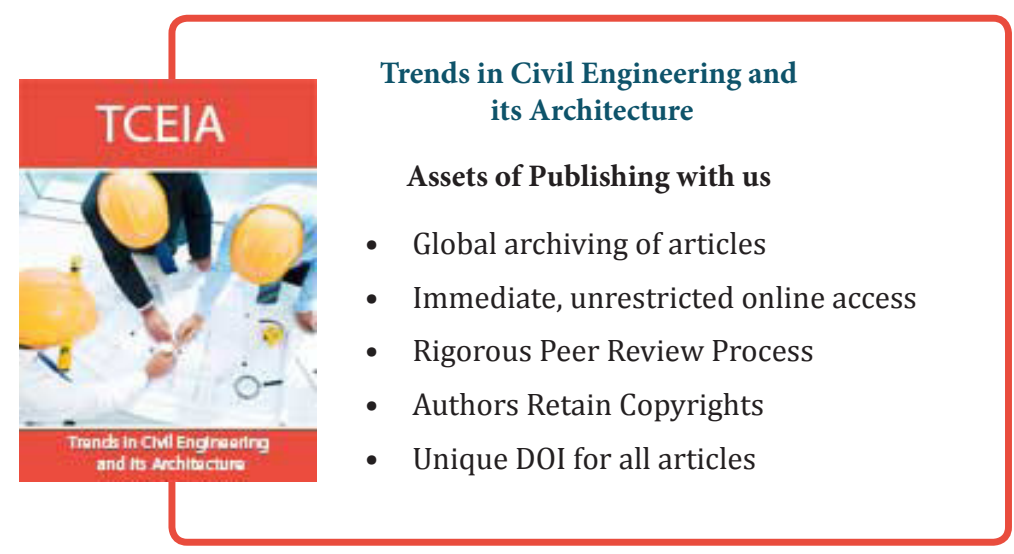

